\title{
ASSESSMENT OF BLENDED LEARNING MECHANISMS AND MODELS
}

\author{
ADAM STECYK \\ University of Szczecin, POLAND \\ e-mail: adam.stecyk@wzieu.pl
}

\begin{tabular}{l|l}
$\begin{array}{l}\text { RECEIVED } \\
\text { ACCEPTED }\end{array}$ & $\begin{array}{l}20 \text { April } 2018 \\
12 \text { July } 2018\end{array}$ \\
JEL \\
CLASSIFICATION \\
I21, I23, I25, 032 \\
KEYWORDS
\end{tabular}

ABSTRACT The aim of the article is to present the latest approach to blended learning, also known as hybrid teaching. The first part of the article presents four basic blended learning models such as rotation, flex, a la carte and enriched virtual model. The second part of the article presents the latest research carried out at the Faculty of Management and Economics of Services at the University of Szczecin on the subject of a functioning blended learning model and its assessment by students (The research was conducted among students in January 2018). In addition, some mechanisms occurring in hybrid teaching using a specific e-learning platform were also analyzed. Because blended learning is currently the most popular form of teaching, there is a need for constant monitoring of emerging new solutions that can be used in higher education.

\section{Introduction}

The teaching and learning environment is embracing a number of innovations and some of these involve the use of blended learning teaching model. In other words, the blended learning model changes the traditional classroom by delivering educational content through e-learning system in addition to/instead of participating in didactic process personally. Learning requirements and preferences of each student seem to be different. 
Universities must use a blend of learning strategies in their way to get the suitable content in the applicable format to the main participants (students and lecturers) at the right time. Blended learning combines multiple delivery media that are designed to complement each other and promote learning and application-learned behavior. In terms of Bloom's revised taxonomy (Figure 1), this means that students are doing the lower levels of cognitive work such as, gaining knowledge and comprehension out of the campus, and they are focused on the higher forms of cognitive work such as application, analysis, synthesis, and evaluation at the university, where they have the support of their tutor (Scott, 2003).

\section{Blended learning models in higher education}

So what is blended learning in particular? It can be summarized that blended learning in higher education is a formal education program in which a student learns, at least in part, through online delivery of content and instruction with some element of student control over time, place, path, and pace and at least in part at a supervised university location away from student's home. In other words blended learning mode combines on-line training and brick-and-mortar traditional learning model. (blended learning is defined as learning that takes place partially over the Internet. This definition excludes purely print-based correspondence education, broadcast television or radio, and stand-alone educational software programs that do not have a significant Internet-based instructional component) (Alonso, 2005).

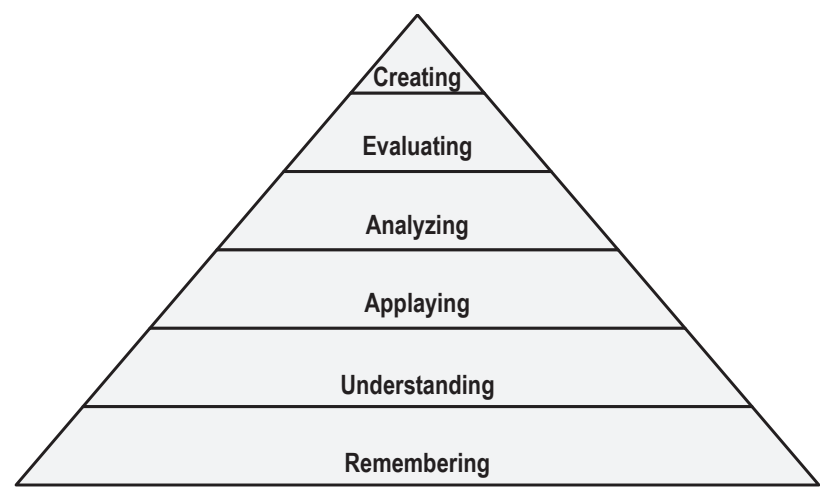

Higher level skills: apply, analyze, evaluate, create - activities completed face to face

Lower level skills: remember, understand - activities completed on-line

Figure 1. Bloom's taxonomy (revised)

Source: own elaboration.

For most lecturers the reason to offer blended learning will be to improve the level of teaching quality and the teaching results. It is also a big concern to university leaders who will be looking at the financial side of blended learning models which can offer a big savings on the educational services market. It is also important for students to get personalized learning experience which will allow them to find a suitable job in the future. In fact, according to a 2010 study from the U.S. Department of Education, blended learning classes produce statistically better results than their face-to-face, non-hybrid equivalents (US Department of Education, 2010). 
One of the greatest advantages offered by blended learning model is its ability to help lecturers with differentiation ways of teaching. The combination of face-to-face instruction and online learning opportunities allows for individualization, flexibility, and greater chance for future success. There are several models of blended learning from which to choose (Picciano, 2014), so that they can implement a high level of quality in higher education:

1. Rotation model.

2. Flex model.

3. A La Carte model (formerly Self-Blended model).

4. Enriched Virtual model.

The rotation model allows students to rotate through stations on a fixed schedule, where at least one of the stations is an online learning station. In other words, in this form of blended learning, students rotate between different stations on a fixed schedule - either working online or spending face-to-face time with the teacher. There are several types of rotation model:

- station (rotating through on-line stations, face-to-face meetings and collaborative activities),

- lab (online learning occurs in a dedicated computer lab, e.g. a math laboratory),

- individual (rotating through stations, but on individual schedules set by a teacher or software algorithm).

Flipped classroom (learning at home via online coursework and lectures; face-to-face class time is used for teacher-guided practice or project).

Despite the fact that this model is most often used in primary education, it can also be successfully used in blended learning mode in higher education.

Another blended learning model is called flex model and it heavily relies on online instructional delivery, with teachers acting as tutors rather than as primary deliverers of instruction. In other words, in flex model the in which the online learning is the backbone of student learning, even if it directs students to offline activities from time to time. This gives the main course participants more flexibility and more control over the time they use: tutors have time individual work with students because they are generally no longer delivering knowledge in front of a class, and students can move through the lessons and lectures at their own pace. This model can give students a high degree of control over their learning.

The next blended learning model is model A La Carte, known also as a Self-Blended model. This hybrid is an education framework in which students take one or more courses entirely online (at home or at the campus) with an online teacher of record and at the same time continue to have brick-and-mortar educational experiences. It gives students the opportunity to take courses beyond what is already offered at their university. While these individuals will attend a traditional uni environment, they also get some new knowledge through online courses offered remotely. This model is a very good tool to increase the level of teaching and learning quality for highly motivated and fully independent students. 


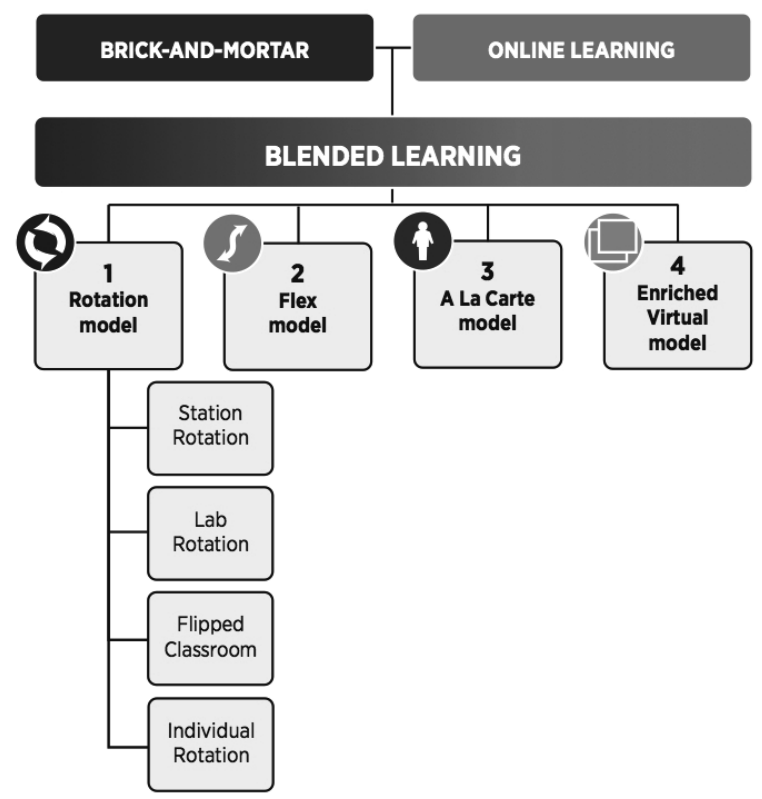

Figure 2. Blended learning models

Source: own elaboration.

The last model to be described is the Enriched Virtual model. It is an alternative to full-time, online courses that allows students to complete the majority of coursework online, at home or outside the campus, but attend university for required face-to-face learning sessions with a tutor. The Enriched Virtual model differs from the Flipped Classroom model because in its programs, students seldom attend the brick-and-mortar campus every day. It also differs from the A La Carte model because it is a whole-university experience, not a course-by-course teaching mode. Figure 2 shows all four described blended learning models.

\section{Blended learning mechanisms evaluation}

The first blended learning project at the Faculty of Management and Economics of Services (University of Szczecin, Poland) has its beginning in 2006, when the contact with E-learning Institute MELCOE of Macquire Innovative University was established. Since then, blended learning tools have undergone evolution and there have been carried out many studies on the e-learning and blended learning models and their impact on the quality level of teaching processes at the faculty. The latest report from January 2018 has been presented below. This study is based on an experiment in which students participated during their study using face-to-face sessions and an on-line courses of a blended learning design in Information Technology subject.

The main issue of blended learning solutions in teaching process was to identify the best quality, friendly-inuse modes, tools and activities. According to the adopted research procedure, an essential step in the verification 
of the proposed concept was to conduct a proper survey ${ }^{1}$. The research was conducted on a sample of 78 students in 3 groups at the Faculty of Management and Economics of Services (University of Szczecin, Poland) in the academic year 2017/2018 (winter semester 2017). The students answered questions about teaching in blended learning mode, and pointed out the pros and cons of educational paths in evaluated subject. The collected empirical data related to the quality issues, allowed the use of statistical analysis to aggregate information and calculate the average value of the results for the specified areas and factors. The results of the study were finally grouped into three ranges:

- the factors determining the satisfactory level of quality (4.1-5.0);

- the factors determining the acceptable level of quality (3.0-4.0);

- the factors determining the unsatisfactory level of quality (less than 3.0).

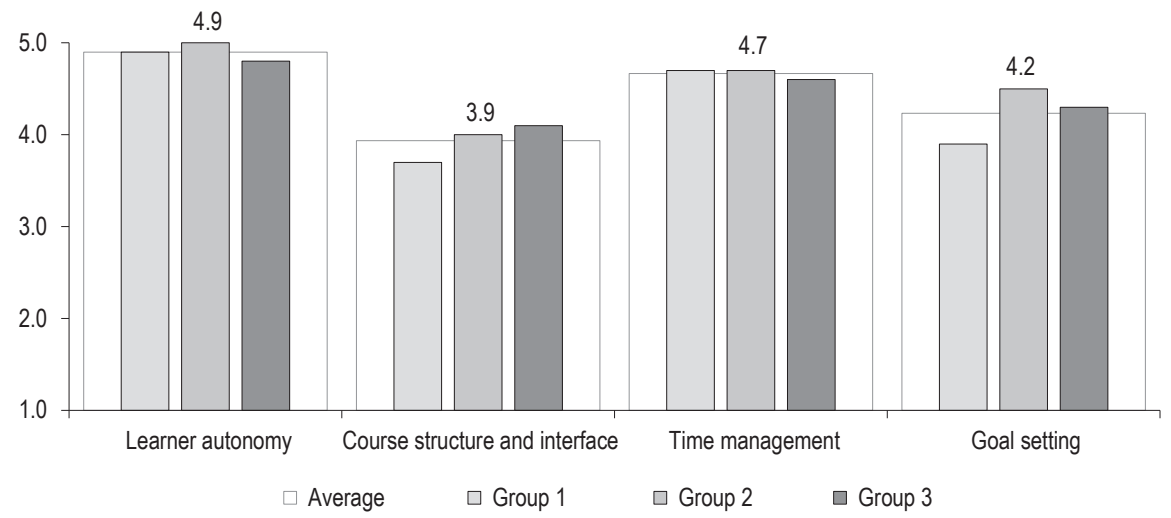

Figure 3. Attitudes towards blended learning model survey

Source: own elaboration.

The first dimension of test and analysis was the attitudes towards used blended learning model. The highest rated factor was learner autonomy (4.9) which which shows that being independent of place and time in learning is a big advantage for students. Students also highly rated time management factor (4.7), what indicates more time efficiency in the blended learning model compared to the traditional teaching model. On the next places were two factors: goal setting (4.2) and course structure (3.9). While the first factor requires re-evaluation of course objectives and is possible to be performed by the teacher, the second factor is dependent on the e-learning system used at the University.

${ }^{1}$ The applied research model used SERVPERF method and Likert scale: 1 - strongly disagree, 2 - disagree, 3 - neutral, 4 - agree 5 - strongly agree (Cronin, Taylor, 1994; Parasuraman, Zeithaml, Berry, 1994). 


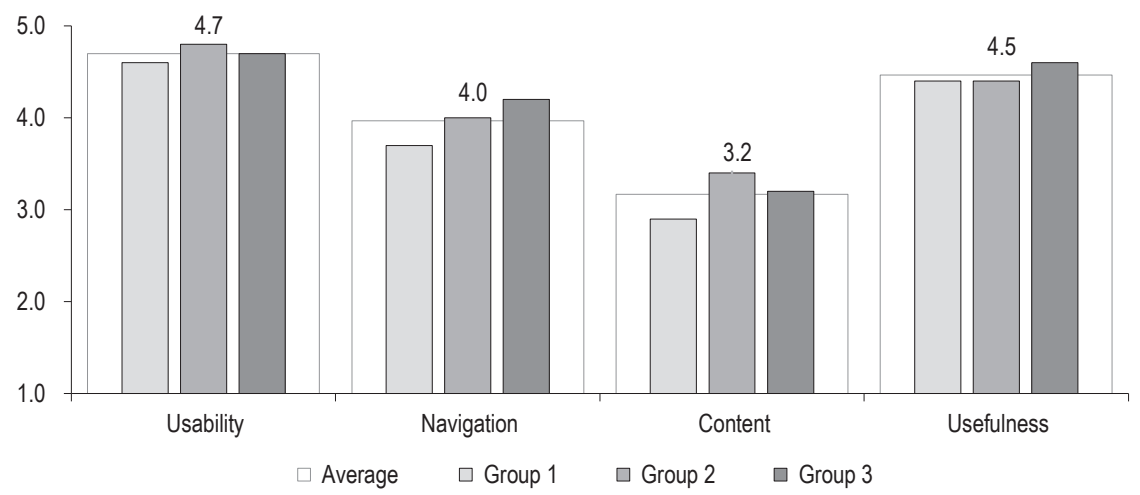

Figure 4. Online tools and resources survey

Source: own elaboration.

The highest estimated factor was usability (average 4.7), which means that the proposed teaching blended learning mode is highly regarded by the participants. In the second place was the usefulness (4.5) while the next two: navigation and content, were estimated at the level of 4.0 and 3.2. Despite the fact that all the factors was admitted to a group of factors determining the satisfactory or acceptable level of quality, it should be noted that one of them (content) slightly exceeded the limit of 3.0. This means that one needs to pay attention to methodical aspects in the future, and to modifications of the blended learning tools responsible for the teaching model and the content. The last two determinants that were qualified to the group of factors describing the acceptable level of quality (navigation and content). That indicates that there is a need for discussion about the selected e-learning system and about the tools and software used to create presentation and verification activities.

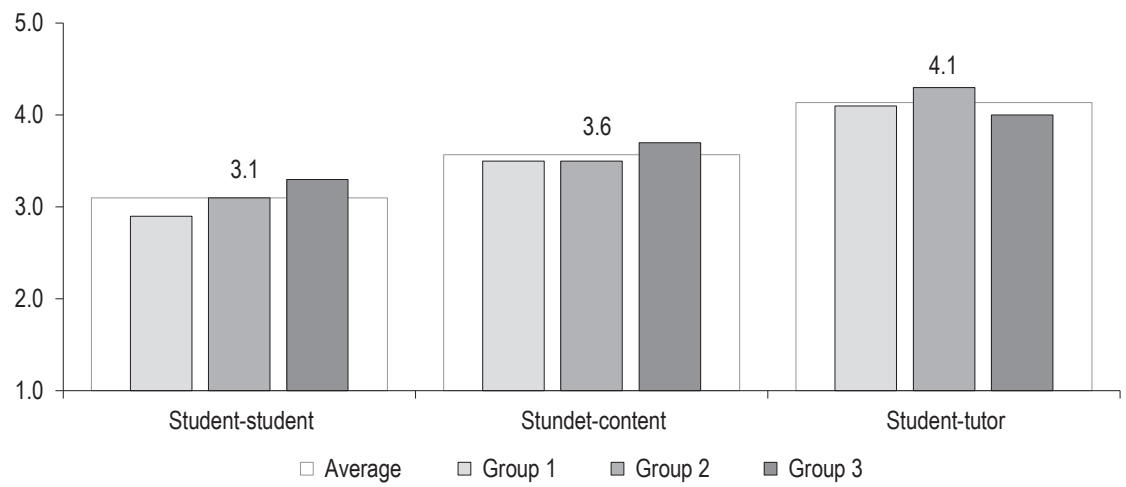

Figure 5. Interaction survey

Source: own elaboration. 
The third survey was conducted about what is important in collaborative teaching, on interactions. Two factors can be described as acceptable (student-student 3.1 and student-content 3.6) while student-tutor interaction was qualified to the group of factors describing the acceptable level of quality (4.1). Nevertheless, it is clearly visible that the ratios slightly exceeded the set limits, which means that one should think about the evaluation of selected interaction mechanisms and their modification for subsequent blended learning courses.

The presented research results are a part of a broader analysis and monitoring of blended learning solutions at the Faculty of Management and Economics of Services. In comparison to previous years, the results indicate an upward trend, i.e. an increase level of interest in hybrid teaching, both among teachers and students, as well as an increase in the quality of offered courses, didactic paths and activities.

\section{Conclusions}

The tests carried out together with other analyzes are aimed at improving the quality of building educational programs implemented in the blended learning mode. In addition, they serve to monitor students' opinions on the use of modern ICT technologies in teaching at the academic level. The following issues should therefore be considered:

- defining a methodical approach to blended learning issues and choosing an existing teaching model or developing an original approach,

- defining the stages of building blended learning courses, with particular emphasis on the proportion between traditional teaching and on-line teaching,

- paying attention to the selection and construction of presentation, verification and communication activities, in the context of mutual interactions,

- defining the role of teacher and student in the didactic process, with particular emphasis on the goal setting and the evaluation of individual tasks and the entire course.

\section{Referenences}

Alonso, F. (2005). An instructional model for web-based e-learning education with a blended learning process approach. British Journal of Educational Technology, 217-235.

Cronin, J., Taylor, S. (1994). SERPVERF Versus SERVQUAL: Reconciling Performance-Based and Perceptions - Minus-Expectations Measurement of Service quality. Journal of Marketing, 1 (58), 23-24.

Education, U.D. (2010). US Department of Education. Pobrano z lokalizacji. Retrieved from: https://www2.ed.gov/rschstat/eval/tech/ evidence-based-practices/finalreport.pdf.

Parasuraman, A., Zeithaml, V., Berry, L. (1994). Alternative scales for measuring service quality: A comparative assessment based on psychometric and diagnistic criteria. Journal of Marketing, 3 (70), 201-230.

Picciano, A.G. (2014). Blended Learning: Research Perspectives. New York: Taylor \& Francis.

Scott, T. (2003). Bloom's taxonomy applied to testing in computer science classes. Journal of Computing Sciences in Colleges, $267-274$.

Cite this article as: Stecyk, A. (2018). Assessment of blended learning mechanisms and models. European Journal of Service Management, 3 (27/1), 299-305. DOI: 10.18276/ejsm.2018.27/1-38. 